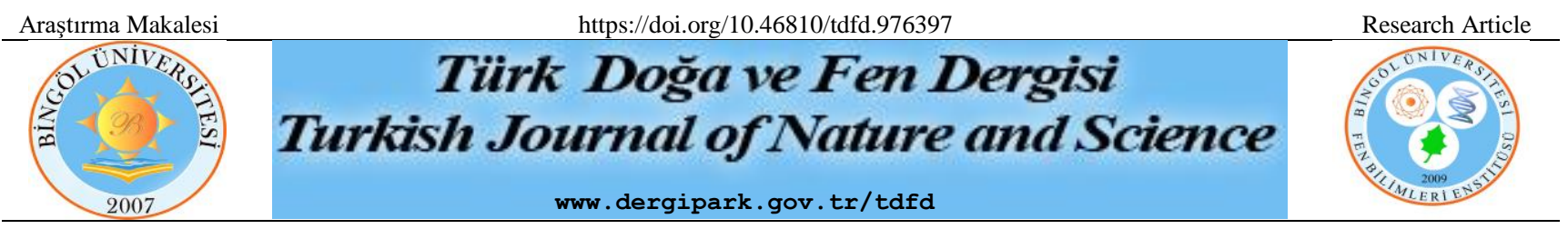

\title{
Anlaşılabilir Sınıflandırma Kurallarının Ayçiçeği Optimizasyon Algoritması ile Otomatik Keşfi
}

\author{
Suna YILDIRIM*1, Güngör YILDIRIM², Bilal ALATAŞ ${ }^{3}$ \\ ${ }^{1}$ Elazığ İl Özel İdaresi, Bilgi İşlem Birimi, Elazı̆̆g, Türkiye \\ ${ }^{2}$ Firat Üniversitesi, Mühendislik Fakültesi, Bilgisayar Mühendisliği Bölümü, Elazığ, Türkiye \\ ${ }^{3}$ Frrat Üniversitesi, Mühendislik Fakültesi, Yazılım Mühendisliği Bölümü, Elazı ğ, Türkiye \\ Suna YILDIRIM ORCID No: 0000-0002-8246-0515 \\ Güngör YILDIRIM ORCID No: 0000-0002-4096-4838 \\ Bilal ALATAŞ ORCID No: 0000-0002-3513-0329 \\ *Sorumlu yazar: sunayildirim23@gmail.com
}

(Alınış: 30.07.2021, Kabul: 30.09.2021, Online Yayınlanma: 31.12.2021)

Anahtar
Kelimeler
Optimizasyon,
Kural
Madenciliği,
Ayçiçeği
Optimizasyon
Algoritması,
Doğruluk

Anahtar

Kelimele

Optimizasyon,

Kural

adenciliğ

Optimizasyon

Doğruluk

\begin{abstract}
Öz: Kural madenciliği, veri madenciliğinin önemli alt dallarından biri olup günümüzde hala üzerinde çalışılan sıcak bir çalışma alanıdır. Nicel nitelik içeren veri setleri üzerinde çalışan standart sınıflandırma yöntemleri genellikle ön işlem aşamalarına ihtiyaç duyarlar. $\mathrm{Bu}$ yapılan ayrıklaştırmalar ise başarım kaybına yol açabilmektedir. Buna ek olarak standart sınıflandırma algoritmalarının kara-kutu yapılarından dolayı kural açıklanabilirlikleri iyi değildir. Bu noktada, sürekli veriler ile çalışabilen optimizasyon algoritmaları, bu dezavantajların üstesinden gelebilir. Bu çalışmada, son yılların başarılı optimizasyon algoritmalarından olan Ayçiçeği Optimizasyon algoritmasını kullanarak verimli bir kural madenciliği gerçekleştirilmiştir. Bunun için, farklı bir temsil biçimi kullanan aday bitki yapısı, bu optimizasyon algoritmasına uyarlanmıştır. Arama uzayı olarak üç farklı disipline ait veri seti kullanılmış ve yöntemin başarımını gözlemlemek için iyi bilinen beş farklı sınıflandırma algoritmasına ait sonuçlar paylaşılmıştır. Elde edilen sonuçlar, optimizasyon temelli yaklaşım ile veri setleri üzerinde herhangi bir ön işlem yapmaya gerek kalmadan açıklanabilir kurallar üretilebileceğini ispatlamaktadır.
\end{abstract}

\section{Automatic Discovery of Comprehensible Classification Rules with Sunflower Optimization Algorithm}

\section{Keywords Optimization, Rule Mining, Sunflower Optimization Algorithm, Accuracy}

\begin{abstract}
Rule mining is one of the important sub-branches of data mining, and it is still a hot topic study area for researchers. Standard classification methods usually require pre-processing steps when working with datasets containing quantitative attributes. On the other hand, discretization at these stages may lead to a loss of performance and accuracy. In addition, due to the black-box nature of standard classification algorithms, rule explicability is not good. At this point, optimization algorithms that can work with continuous data can overcome these disadvantages. This study focuses on rule mining using the Sunflower Optimization algorithm, one of the successful optimization algorithms of recent years. For this, the candidate plant structure using a different representation format was adapted to this optimization algorithm. Data sets from three different disciplines were used as the search space, and the results of five different well-known classification algorithms were shared for performance observations. The results obtained proved that, with the optimization-based approach, explicable rules can be produced without any pre-processing on the data sets.
\end{abstract}

dalıdır. Çıarılan bu kurallar, kontrol sistemlerinde ve sinıflandırma temelli sistemlerde kullanılabilir. Bununla beraber, çıkarılan kuralların doğruluğu kullanılacak sistemin başarısını doğrudan etkileyeceğinden dolayı kural kapsamı metriği burada kritik öneme sahiptir. Bu

\section{GİRiş}

Kural madenciliği, kısaca, bir veri setinden anlamlı ve yorumlanabilir kurallar çıkarabilen veri madenciliği 
metrik özellikle verinin nümerik olduğu durumlarda hatalara karşı daha duyarlı hale gelebilmektedir. Standart sınıflandırma algoritmaları, nicel veriler üzerinde genellikle ayrıklaştırma mekanizması kullandıklarından yaptıkları sinıflandırmalarda kayıplar meydana gelebilmektedir. Sınıflandırma algoritmaları, birkaç küme halinde gruplandırılmıştır ve bu kümeler sıralı iletişim ile katmanlar halinde düzenlenmiştir. Bununla birlikte, topluluk yöntemleri tasarlamak karmaşıktır ve çok fazla hesaplama süresi gerektirir. Ayrica, sınıflandırma yöntemlerinin çoğu yanlış tahminlerde bulunursa, bu da topluluk metotlarının iyi performans vermesini engeller [1,2]. Sinıflandırma algoritmalarının çoğu kara-kutu yaklaşımlardır. Diğer taraftan, veri kümeleri içerisinde doğru kurallar kadar, anlaşılır kuralların da çıkarılması açıklanabilir yapay zeka, makine öğrenmesi ve sinıflandırma kuralları madenciliğinde de önemlidir [3]. Ayrıca, sayısal özniteliklerden oluşan veri kümeleri içinde ilginç, anlaşılır ve doğru sınıflandırma kurallarının madenciliği daha karmaşıktır. Nicel veri kümeleri için sınıflandırma algoritmaları, bilgi kaybına neden olabilecek bir ön işlem olabilecek bir tür ayrıklaştırma gerçekleştirir. Bu durumda, veri seti değiştirilmiş olur. Böylece, keşfedilen sınıflandırma kuralları, değiştirilen veri kümesinin modeline aittir. Veri kümesini değiştirmek mantıksızdır ve ayrıca hesaplama yükü gerektirir [4]. Veri kümesini değiştirmeden sınıflandırma yöntemini uyarlamak daha mantıklıdır. Nicel öznitelikler için ilgili aralıkların bulunmasını ve yüksek kaliteli nicel sınıflandırma kurallarının çoklu amaçlarla madenciliğini yalnızca bir adımda entegre etmek, hız ve doğruluk açısından çok daha anlamlı görünmektedir. Veriler çoklu sinıflara, çoklu özelliklere sahipse ve oldukça dengesizse, sınıflandırma işlemi daha karmaşık hale gelir [5]. Olası öznitelik kombinasyonlarının sayısı çok büyük olduğunda, klasik yöntemlerin performansları düşüktür.

Kural madenciliği farklı disiplinlerde ortaya çıkan problemlerin çözümünde kullanılmaktadır. Gündoğan ve ark. [6] sınıflandırma kuralı madenciliği için bir genetik algoritma (GA) kullanmışlardır. Yöntemleri, genelleştirilmiş tek tip popülasyon yöntemi ve bundan ilham alan tek tip bir operatör kullanarak anlaşılır EĞER-İSE kurallarını keşfetmektedir. Uygulama için meme kanseri ve dermatoloji veri setlerini kullanmışlardır. Pourpanaha ve ark. [7] veri sınıflandırması ve kural çıkarımı için hibrit model önermiştir. Çalışma iki aşamadan oluşmaktadır. İlk aşama, sınıflandırma için Q-öğrenmeyi, ikinci aşama ise Q-öğrenme'den genetik algoritma ile kural çıkarımını başarmaktır. Tasarlanan yöntemin etkinliği Iris, PID, Dermatology, Glass, Sonar, Wine, Statlog (Heart) veri setleri üzerinde ispatlanmıştır. Tripathy ve ark. [8] sınıflandırma kuralı madenciliği için MTACO-Miner (Modified Threshold Ant Colony Optimization-Miner) olarak adlandırılan gelişmiş bir karınca kolonisi optimizasyon algoritması önermişlerdir. Uygulama, Wisconsin Diagnostic Meme Kanseri veri setini kullanılmış ve sonuçlar MTACO-Miner ve Ant-Miner algoritmaları ile karşılaştırılmıştır. Taboada ve ark. [9] yaptıkları çalışmada, genetik ağ programlama kullanan bulanık sınıflandırma kurallarına dayalı bir sınıflandırma yöntemi sunmuşlardır. Genetik ağ programlamanın karakteristiğinin, önerilen modelin formüle edilmesini ve kullanılmasını kolaylaştırdığını göstermişlerdir. Önerilen algoritmanın performansları diğer ilgili algoritmalar ile karşılaştırılmış ve deneysel sonuçlar, önerilen modelin avantajlarını ve etkinliğini gösterdiğini belirtmişlerdir. Dehuri ve ark. [10], çok amaçlı sınıflandırma kuralı madenciliği için bir Genetic Expression ProgrammingGEP yaklaşımı önermişlerdir. Amaç olarak, sınıflandırma doğruluğu ve anlaşılabilirlik kriterleri dikkate alınmıştır. GEP yaklaşımının diğer algoritmalara göre daha verimli olduğunu ve kural ağaç tabanlı genetik programlama siniflandirıcilarına kiyasla daha kısa çözümler üretme eğiliminde olduğunu belirtmişlerdir. Önerilen yöntemin kuralın anlaşılırlığını arttırdığını savunmuşlardır. GEP sınıflandırıcısı birkaç kıyaslama veri seti ile test edilmiş ve tatmin edici sonuçlar elde edildiği makalede gösterilmiştir. Zhong-Yang ve ark. [11] yaptıkları çalışmada, genetik algoritma ve tabu arama ile birleştirilmiş gelişmiş bir hibrit genetik algoritma kullanan bir sinıflandırma yöntemi kullanmışlardır. Sınıflandırma doğruluğunu artırmak ve ayrıca sınıflandırma kural kümesini yoğunlaştırmak için bir kural çıkarma yaklaşımını da vermişlerdir. Alınan sonuçlar dört kıyaslama veri seti üzerinde doğrulanmış ve diğer algoritmalarla karşılaştırılmıştır. Bu deneylerin, önerilen yöntemin iyi bir performansa sahip olduğunu ve bir dizi özlü, verimli ve anlaşılır sınıflandırma kurallarını keşfetme yeteneğine sahip olduğunu gösterdiğini belirtmişlerdir.

Optimizasyon yöntemleri, kısıtlamaları karşılayan bir dizi mevcut parametreden en iyi değerleri belirleyerek problemleri çözmek için kullanılır. Akıllı metasezgisel algoritmalar, çok farklı alanlarda uygulandığında, üretilen sonuçların sağlamlığı ve basitliği nedeniyle arama ve optimizasyon problemlerinin çözümünde kesin klasik algoritmalara göre daha fazla popülerlik kazanmıştır [12, 13]. Pek çok problemin çözümünde başarı gösteren akıllı optimizasyon algoritmaları kural madenciliğinde de etkili sonuçlar üretebilmektedir [6, 14, 15]. Bu çalışma, bitki zekası temelli optimizasyonu ile kural madenciliğine odaklanmıştır. Son yılların başarılı metasezgisel yaklaşımlarından olan Ayçiçeği Optimizasyon Algoritması (AOA) kural madenciliği için yeniden uyarlanmıştır. Bu çalışma, AOA'nın kural madenciliğine uygulanabilirliğine odaklanmaktadır. $\mathrm{Bu}$ algoritma, yazarların bildiği kadarıyla, daha önce kural madenciliğinde kullanılmamıştır. Bununla beraber, literatürdeki diğer uygulamalara benzer olarak, standart AOA da doğrudan kural çıkarım sistemlerine uygulamaz. Sürekli optimizasyon problemlerine yönelik olan AOA'nın bu amaç için uyarlanmıș versiyonuna ihtiyaç vardır. $\mathrm{Bu}$ uyarlama için kural çıkarım adaylarının temsil biçimlerinin doğru belirlenmesi gerekmektedir. Uyarlanmış AOA'da bitki adaylar için üç nitelikli bir temsil formatı kullanılmıştır. İlgili veri seti ise arama uzayı olarak kullanılmış ve aday bitkiler bu uzayda kural keşfi için modellenmiş bir amaçla uygunluk fonksiyonu önerilmiştir. $\mathrm{Bu}$ amaçla makalede ilk olarak standart AOA açıklanacak ve daha sonra farklı bir temsil biçimi kullanan uyarlanmış AOA versiyonu detaylandırılacaktır. 
Çalıșmanın bundan sonraki organizasyonu şu şekildedir; klasik AOA'nın literatür özeti ve mantıksal detayları ikinci bölümde sunulacaktır. AOA temelli yeni sınıflandırma kural keşif yaklaşımı üçüncü bölümde sunulacaktır. Performans testleri ve elde edilen sonuçlar dördüncü bölümde, sonuç değerlendirmeleri ise beşinci bölümde paylaşılacaktır.

\section{AYÇIÇEĞİ OPTIMIZASYON ALGORITMASI (AOA)}

Yapılan çalışmanın detaylarına geçmeden önce başarılı bir bitki zekası algoritması olan AOA hakkında detay bilgilerin verilmesi faydalı olacaktır. Ayçiçeği algoritmasının tercih edilmesinin iki önemli sebebi bulunmaktadır. Birincisi, kural çıkarım problemlerinde bitki zekası temelli yaklaşımlar bilindiği kadarıyla önceden çalışılmamıştır. Bu amaçla bu tip algoritmaların performansları ölçebilecek bir çalışmaya bu alanda ihtiyaç vardır. İkincisi dahili döngü prensibi kullanan AOA'nın yüksek performansı diğer bitki zekası temelli yaklaşımlara göre avantaj sağlamaktır. Bu nedenlerden dolayı AOA bu problemin çözümü için seçilmiştir. Bunun için bu bölümde öncelikle bu algoritmaya ait literatür özeti verilerek çalışma mekanizmasına ait detay bilgiler paylaşılacaktır. Daha sonra, kural çıkarım için uyarlanmış AOA versiyonu detaylandırılacaktır.

AOA'nda, ayçiçeği bitkilerinin güneşe yönelim hareketlerinden esinlenilmiştir. Algoritmada temel prensip, güneş olarak adlandırılan en iyi çözüme ulaşmaktır. Literatürde yeni olmasına karşın bazı problemlerin çözümünde başarılı sonuçlar üretmeyi başarmıştır. Qais ve ark. [16] yaptıkları çalışmada bazı parametre seçimleri için AOA'nı kullanarak fotovoltaik modüllerin modellenmesi ve simülasyonunu gerçekleştirmişlerdir. Standart AO parametrelerini kullanarak bile başarılı sonuçlar aldıklarını kaydetmişlerdir. Gomes ve ark. [17], plaka benzeri yapıların hasar tespiti için bir optimizasyon yaklaşımı önermiş ve önerilen yöntemin verimliliğini; genetik algoritma, AOA ve geliştirilmiş bir AOA'nı kullanarak karşılaştırmalı olarak sunmuşlardır. Bu sonuçlara bağlı olarak önerilen yaklaşımın genetik algoritmalara göre daha iyi sonuçlar verdiği iddia edilmiştir. Yuan ve ark. [18], proton değişim membranlı yakıt hücresi (PEMFC Proton Exchange Membrane Fuel Cell) modellerinde parametrelerin optimum seçimi için yeni bir metodoloji önererek, PEMFC yığınının tahmini ve gerçek çıkış voltajı arasındaki hata karesi değerinin toplamını en aza indirmek için geliştirilmiş bir AOA sunmuşlardır. Geliştirilen AOA'nda, kendi kendine uyarlanabilir ağırlıklandırma kullanılarak en iyi çözüme ulaşma hedeflenmiştir. Hussein ve ark. [19] ise yaptıkları çalışmada, AOA'nı Proportional Integral (PI) kontrolör parametrelerini seçmek için kullanmışlardır. Elde ettikleri sonuçları Parçacık Sürü Optimizasyon algoritması sonuçları ile kıyaslamışlardır. Shaheen ve diğ. [20], güç sistemleri alanında optimum güç akış1 problemini çözmek için AOA'nı kullanan yeni bir girişim sunmuşlardır. Parçacık sürü optimizasyonu ve genetik algoritmaları ile karşılaştırmalı olarak sunulan
AO Algoritması sonuçlarının daha başarılı olduğu bu çalışmada gösterilmiştir. Alshammari ve ark. [21] ise Logistic kaotik haritalama metodunu kullanan bir AOA geliştirerek, bunu güç sistemi stabilizatörlerinin optimal ayarını yapmak için kullanmışlardır. Farklı test fonksiyonlarını kullanarak, kaotik AOA'nın, kullanılan diğer algoritmalardan daha iyi performans gösterdiğini belirtmişlerdir.

Ayçiçeği Optimizasyon algoritmasının temelinde, ayçiçeklerinin güneş 1şınlarını takip etme hareketleri yatar [22]. Ayçiçeklerin (adayların) hedefi, güneşin bulunduğu yöne doğru yönelip en iyi pozisyonu bulmaktır. AOA mekanizmasında, adaylar, eğer güneşe yakın iseler bulundukları yeri korumak ve eğer uzak iseler daha büyük yönelimler gösterip güneşe yaklaşmak isterler. Lokasyonlarını güncellemenin yanında, komşu olan ayçiçekleri ile tozlaşarak yeni bireyler de üretebilirler. Gerçek dünyada milyonlarca tozlaşma oluşurken, algoritmada kolaylık olması için her ayçiçeğinin bir tozlaşma gerçekleştirdiği varsayılmıştır. AOA'da, ilk aşama, başlangıç popülasyonu oluşturmaktır. Başlangıç popülasyonu oluşturulduktan sonra çözüme en yakın birey, güneş olarak adlandırılır. Güneş belirlendikten sonra, güneşin pozisyonuna göre diğer bireylerden komşu olanlar, kendi aralarında tozlaşarak yeni bireyler oluştururlar. Yeni bireyler üretildikçe arama uzayının boyutu artar ve bunun engellenmesi için belli bir oranda ayçiçeği bireyleri elenir. Gerekli güncelleme ve yeni birey üretiminden sonra bu süreçler, sonlandırma kriteri sağlanana kadar iteratif şekilde devam ettirilir.

Algoritmada önemli prensiplerden biri ayçiçeklerinin güneşe yöneliminin temsilidir. Popülasyondaki anlık en iyi çözüm olan güneş $\left(X^{*}\right)$, diğer ayçiçeği bireylerine $\left(X_{i}\right)$ referans olur. $n_{p}$ sayıda birey içeren popülasyonun güneşe yönelimi $\mathrm{s}_{\mathrm{i}}$ ile gösterilir ve genel ifadesi Denklem 1'deki gibidir.

$$
s_{i}=\frac{X^{*}-X_{i}}{\left\|X^{*}-X_{i}\right\|}, \quad i=1,2, \ldots, n_{p}
$$

Algoritmanın en iyiye ilerleyişi yönelim olarak adlandırılır ve Denklem 2 ile ifade edilir. Yönelim, iki temel parametreye dayalıdır. Bunlar $\lambda$ eylemsizlik katsayısı ve i. birey ve (i-1). birey arasındaki tozlaşma olasılığını ifade eden $P_{i}^{\prime}$ dir. Genel ifadeden de görüleceği üzere güneşe yakın bireyler küçük adımlarla güneşe yönelirken, daha uzak bireyler daha büyük adımlarla yönelim sağlamaya çalışacaklardır.

$$
d_{i}=\lambda P_{i}\left(\left\|X_{i}+X_{i-1}\right\|\right)\left\|X_{i}+X_{i-1}\right\|
$$

Klasik AOA'nda her iterasyonda güneşe uzak olan bazı bireyler, popülasyondan çıkarma oranına $(\mathrm{O})$ göre arama sürecinden çıarılmakta ve yerine yeni bireyler üretilmektedir. $\mathrm{Bu}$ yeni bireyler, her iterasyonda popülasyona katılarak farklı keşif noktalarının bulunmasına yardımcı olmaktadır. Bunun dışında diğer bireylerin yeni konumlarının belirlenmesinde, global minimum adaylarını kaçırmamak için maksimum yönelim miktarı değerine de dikkat etmek gerekir. Bu 
temel prensip, Denklem 3 ile sağlanmaktadır. $\mathrm{Bu}$ denklemde, $X_{\max }$ ve $X_{\min }$ üst ve alt sınır değerlerini, $\mathrm{N}_{\text {pop }}$ ise popülasyondaki toplam birey sayısını belirtmektedir. Yeni bireye ait değerin hesaplanmasında, Denklem 4 kullanılmaktadır. AOA'nın bu temel adımları ve mantıksal fonksiyonları, Algoritma 1'de paylaşılan sözde kodda görülebilir.

$$
\begin{gathered}
d_{\text {max }}=\frac{\left\|X_{\max }-X_{\min }\right\|}{2 N_{\text {pop }}} \\
\vec{X}_{i+1}=\vec{X}_{i}+d_{i} \vec{s}_{i}
\end{gathered}
$$

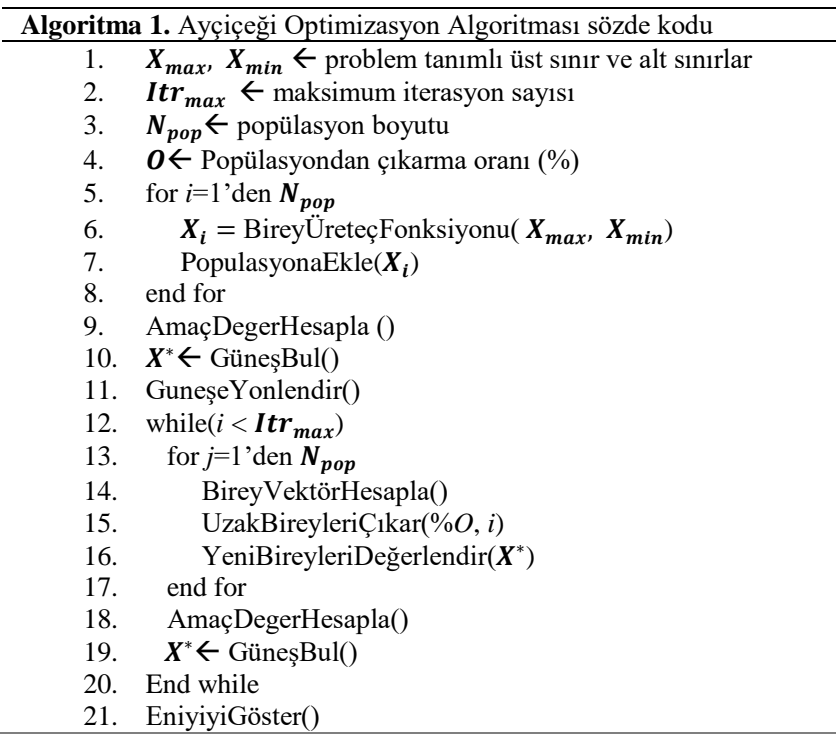

\section{AOA TABANLI OTOMATIK SINIFLANDIRMA KURAL MADENCİLİĞİ SISTEMI}

Bu çalışma, yazarların bildiği kadarıyla, daha önce kural madenciliğinde kullanılmayan AOA'nın kural madenciliğine uygulanabilirliğine odaklanmaktadır. Bununla beraber, literatürdeki diğer uygulamalara benzer olarak, standart AOA da doğrudan kural çıkarım sistemlerine uygulanmaz ve sürekli optimizasyon problemlerine yönelik olan AOA'nın bu amaç için uyarlanmış versiyonuna ihtiyaç olduğu düşünülmektedir. $\mathrm{Bu}$ uyarlama için kural çıkarım adaylarının temsil biçimlerinin doğru belirlenmesi gerekmektedir.

Sınıflandırma kural madenciliği için kullanılan birçok yöntem ve algoritma vardır [23, 24]. Bu sınıflandırma algoritmalarının ve modellerinin çoğu kara-kutu tabanlı yaklaşımlardır. Ancak, anlaşılabilir kurallar, veri setlerinde olduğu kadar, doğru kurallara ulaşılmasını hedefleyen açıklanabilir yapay zeka veri madenciliğinde de oldukça önemlidir [3]. Ayrıca, sayısal özelliklerden oluşan veri setinde ilginç, anlaşılabilir ve doğru sınıflandırma kurallarının madenciliği daha karmaşıktır. Nicel veriler için sınıflandırma algoritmaları, bilgi kaybına neden olabilecek bir ön işlem yaparak bir tür ayrıklaştırma gerçekleştirir. $\mathrm{Bu}$ durumda, veri madenciliğinde veri seti problemi değiştirilir. $\mathrm{Bu}$ yüzden; keşfedilen sınıflandırma kuralları değiştirilmiş veri setinin modeline ait olur. Veri setini değiştirmek hataya açıktır ve ayrıca hesaplama yükü gerektirir [4]. Veri seti değiştirildiğinde asıl çözümü istenilen sınıflandırma probleminin doğruluğu da azalacaktır. Bu sebeple, veri seti değiştirmeden sınıflandırma yöntemini uyarlamak daha mantıklıdır [14]. Nicel özellikler için ilgili aralıkları bulmanın ve yüksek kaliteli nicel sınıflandırma kurallarının madenciliğinin birden fazla hedefle tek bir adımda birleştirilmesi hız ve doğruluk açısından çok anlamlı görünmektedir.

Bu çalışma, nicel kural çıkarım problemlerinde, $n$ bireyli popülasyondaki her çözüm için farklı bir temsil biçimini esas almıştır [14]. Bu temsil biçiminde, $d$ (nitelik sayısı) boyutlu bir $X_{i}$ çözümü, $X_{i}^{b}, X_{i}^{a}$ ve $X_{i}^{u}(\mathrm{i}=1,2, \ldots, n)$ olmak üzere üç adet alt veri içermektedir. $X_{i}^{b}=$ $\left(x_{1}^{b}, x_{2}^{b}, \ldots, x_{j}^{b}, \ldots, x_{d}^{b}\right)$, bir çözümün her bir niteliği için ikili bir veri tutar. Bir $x_{j}$ niteliğinin, çözümün kuralına eklenip eklenmeyeceği $x_{j}^{b}$ değeri ile belirlenir. Başlangıç popülasyonunda $x_{j}^{b}, t($.) rastgele üreteç fonksiyonu ve daha önceden tanımlanmış bir “ $\delta$ ” eşik değeri ile belirlenir. Bu işlem Denklem 5 ile hesaplanmıştır.

$$
=\left\{\begin{array}{c}
1\left(\text { ĕger } x_{j} \text { kuralda kullanılmışsa }\right) x_{j}^{b}>\delta, \delta \in[0,1 \\
0\left(\text { ĕger } x_{j} \text { kuralda kullanılmamışsa }\right) \text { diğer }
\end{array}\right.
$$

$X_{\mathrm{i}}^{a}=\left(x_{1}^{a}, x_{2}^{a}, \ldots x_{j}^{a}, \ldots x_{d}^{a}\right)$, bir çözüme ait kuralın her niteliği için hesaplanan alt limitleri gösterirken, $X_{\mathrm{i}}^{u}=$ $\left(x_{1}^{u}, x_{2}^{u}, \ldots x_{j}^{u}, \ldots x_{d}^{u}\right)$ ise ilgili çözüm kuralındaki niteliklerin üst limitlerini gösterir $\left(x_{d}^{a}, x_{d}^{u} \in \mathrm{R}\right)$. Arama uzayında alt değeri $N^{a}$ ve üst değeri $N^{u}$ olan "j" niteliği için, " $N^{a} \leq x_{j}^{a}<x_{j}^{u} \leq N^{u}$ " koşulu her iterasyonda her zaman geçerlidir. İterasyonlar süresince her bir aday kendine ait $X_{i}^{b}, X_{i}^{a}$ ve $X_{i}^{u}$ değerlerini yeniden hesaplar. İterasyonların sonunda $x_{j}^{b}>\delta$ şartını sağlayan her nitelik " $X_{i}$ ” çözümünün kuralına eklenir. Veri setindeki her sınıf için kural madenciliği optimizasyonu ayrı ayrı gerçekleştirilmiştir. Bu, ana veri setinin (arama uzayının) her bir sınıf için alt uzaylara bölündüğü ve her optimizasyon işleminin ilgili alt uzayda gerçekleştiği anlamına gelmektedir. Bir çözümün $X_{i}^{b}, X_{i}^{a}$, ve $X_{i}^{u}$ değerleri, ilgili arama uzayındaki her veri için kontrol edilir ve amaç fonksiyonunun uygunluk değerini hesaplamak için kullanılır. Örneğin, "S" sınıfı için gerçekleştirilen bir kural madenciliği optimizasyon işleminde, bir çözümün kendi kuralında $1 ., 3$. ve 5. nitelikleri kullandığını varsayalım $\left(x_{1}^{b}, x_{3}^{b}\right.$, ve $x_{5}^{b}>$ $\delta, i$.iterasyonda). $\mathrm{Bu}$ durumda, aday çözümün " $k$ " verisi $\left(\mathrm{X}_{k_{1}}, \mathrm{X}_{k_{2}}, \ldots, \mathrm{X}_{k_{m}}\right)$, için kontrol edilmesi Denklem 6'ya göre gerçekleştirilecektir.

$$
\text { e ğer } \mathrm{x}_{1}^{\mathrm{a}} \leq \mathrm{X}_{k_{1}} \leq \mathrm{x}_{1}^{\mathrm{u}} \text { ve } \mathrm{x}_{3}^{a} \leq \mathrm{X}_{k_{3}} \leq \mathrm{x}_{3}^{\mathrm{u}} \text { ve } \mathrm{x}_{5}^{\mathrm{a}} \leq \mathrm{X}_{k_{5}} \leq \mathrm{x}^{\mathrm{l}}
$$

$\mathrm{Bu}$ hesaplama işlemi, amacın uygunluk değerini hesaplamak için kullanılmaktadır. Çalışmada, amaç fonksiyonu olarak sınıflandırmanın "doğruluk" değeri alınmıştır. $X_{i}$ çözümünün "doğruluk" değerini bulmak için ilgili " $S$ " sınıfina ait her veri için Denklem 6'daki koşul tek tek kontrol edilir. $\mathrm{Bu}$ işlemlerin sonucunda 
doğru pozitif (DP), doğru negatif (DN), yanlış pozitif (YP) ve yanlış negatif (YN) değerleri elde edilir. Bunun için, Tablo 1'de gösterildiği gibi, ilgili kuralın "eğer" kısmı (İSE öncesi) ve "ise" kısmı (İSE sonras1) ayrı ayrı değerlendirilir. Daha sonra, amaç fonksiyonu olarak kullanılan "doğruluk" değeri, ilgili kuralın DP, DN, YP ve YN değerleri baz alınarak Denklem 7'deki gibi hesaplanır.

Tablo 1. DP, DN, YP ve YN değerlerinin hesaplanmas1

\begin{tabular}{lll}
\hline "eğer" kısmı & "ise” kısmı & İşlem \\
\hline Doğru & Doğru & DP'yi 1 artır \\
Yanlış & Yanlış & DN'yi 1 artır \\
Doğru & Yanlış & YP'yi 1 artır \\
Yanlış & Doğru & YN'yi 1 artır \\
\hline
\end{tabular}

$$
D o \text { ğruluk }=\frac{D P+D N}{D P+D N+Y P+Y N}
$$

DP; kuralın hem sol hem de sağ tarafinın doğru olduğu durum sayısı, DN; kuralın her iki tarafının yanlış olduğu durum sayısı, YP; kuralın sol tarafının doğru, sağ tarafının yanlış olduğu durum sayısı, YN ise kuralın sol tarafinın yanlış, sağ tarafinın doğru olduğu durum sayısıdır. Algoritma 2'de verilen sözde kod, kural çıkarım tabanlı Ayçiçeği Optimizasyon Algoritmasında yukarıda açıklanan süreçlerin işleyişini göstermektedir. Algoritmanın işleyişi iki aşamada gerçekleşmektedir. Birincisi eğitim aşamasıdır. $\mathrm{Bu}$ aşamada eğitim veri setleri için uygunluk değerine göre uyarlanmış AOA çalıştırılır. Algoritma iterasyonları sonunda elde edilen kurallar test verileri için tekrar denenmektedir. Aynı değerlendirme süreçleri bu kez test verileri için yapılır. Elde edilen sonuçlar test verileri ile yapılan deneylere aittir.

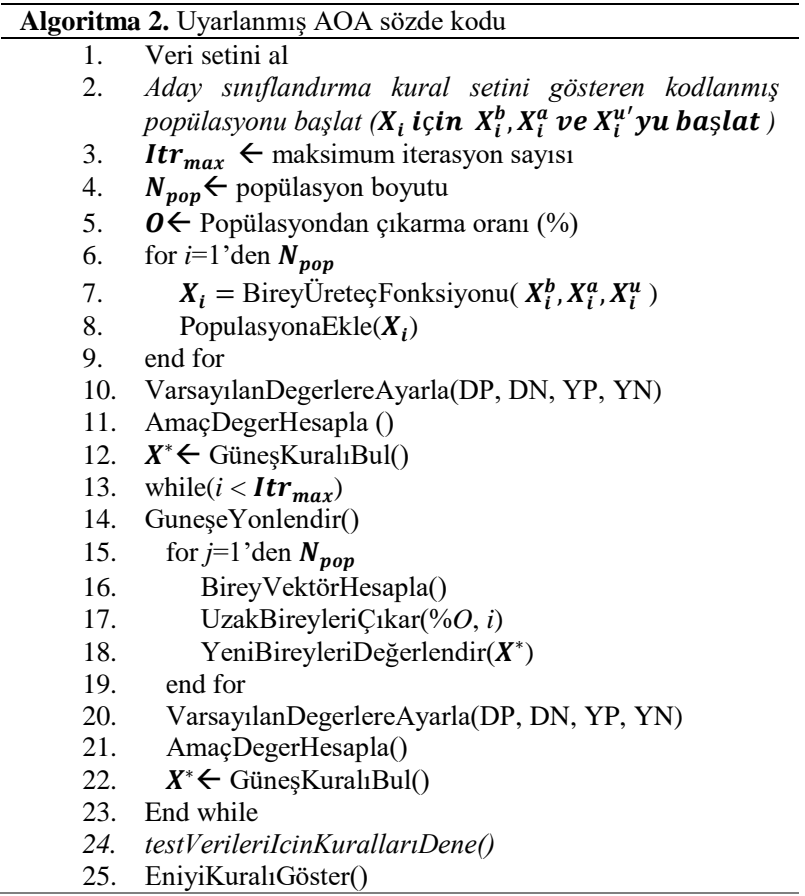

\section{DENEYLER}

Çalışmada, literatürde iyi bilinen üç farklı veri tabanı ile deneyler gerçekleştirilmiştir. Bunlar Ecoli, Iris ve Glass veri setleridir. Amaç fonksiyonu olarak doğruluk kullanılmış ve uygulama platformu olarak Python tercih edilmiștir. Bununla birlikte, elde edilen sonuçların daha sağlıklı değerlendirilmesi için literatürde iyi bilinen sınıflandırma algoritmalarına ait sonuçlar kullanılmıştır. Kullanılan sınıflandırma algoritmaları karar ağacı, k-NN, JRIP, Naive Bayes ve Destek Vektör Makinesi (DVM)'dir. Bu veri setlerinin \%66'sı eğitim, \%34'ü ise test işlemleri için ayrılmıştır. Ayırma işlemi, her bir sınıfın ağırlık oranı dikkate alınarak yapılmıştır. Böylece ana veri setindeki örnek sayılarına göre sınıf ağırlık oranları hem eğitim hem de test veri setlerinde korunmuştur. Kullanılan veri setlerine ait özellikler Tablo 2'deki gibidir. Deneylerde ilk olarak her bir sınıf için eğitim iterasyonları gerçekleştirilmiş daha sonra test süreçleri tamamlanmıştır. İlgili veri seti için algoritmanın doğruluk değeri, içerdiği tüm sınıfların ağırlıklı oranları ile elde edilmiştir. Her bir veri setine ait sınıf ağırlıkları bir sınıfın ilgili veri setindeki örnek sayısına göre belirlenmiştir. Karşılaştırmalı sonuçlar için ilgili veri setleri aynı eğitim ve test veri seti ayırma oranları korunarak standart sınıflandırma algoritmaları için denenmiştir.

Kural çıkarım tabanlı AOA ile yapılan deneylerde veri setlerindeki her bir sınıf için yirmi ayrı deney gerçekleştirilmiştir. Böylece toplamda 340 deney yapılmıştır. İlk deney Ecoli veri seti için gerçekleştirilmiştir. Ecoli veri seti için karşılaştırmalı doğruluk değeri sonuçları Tablo 3'te görülmektedir. Tablo 4'te bu veri seti ile yapilan deneylerden birine ait elde edilen doğruluk değerleri ve çıkarılan kurallar paylaşılmıştır. Bu veri seti için yapılan tüm deneylere ait istatistiksel sonuçlar ise Tablo 5'te verilmiştir. Ecoli veri setinde elde edilen sonuçlar ve sınıf ağırlık değerlerine göre ortalama doğruluk değeri 0,945 olmuştur. Buna göre standart sınıflandırma algoritmaları sonuçları ile karşılaştırıldığında kural çıkarım temelli AOA en başarılı sonucu vermeyi başarmıştır. Standart sınıflandırma algoritmalar içinde en başarılı sonuç Naive Bayes en düşük sonuç ise Karar Ağacı tarafından elde edilmiştir. Tablo 4 ve 5'ten görüleceği gibi AOA başarımı düşük yoğunluk değerli sınıflarda daha yüksektir. Yüksek yoğunluk sınıflarda ise ortalama başarım 0,850 'nin altına inmemiştir. Standart sınıflar içerisinde en yüksek doğruluk değeri sırasıyla Naive Bayes ve DVM tarafından elde edilmiştir. En düşük başarım ise karar ağacına aittir. $\mathrm{Bu}$ veri seti ile yapılan deneylere ait sonuçların dağılımı Şekil 1'de verilmiştir. Şekilden de görüleceği üzere neredeyse tüm sınıflarda başarım genellikle $0.85^{\prime}$ 'in üzerindedir.

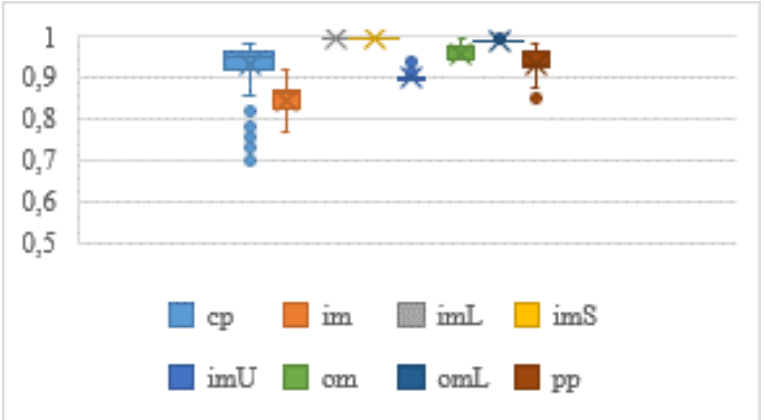

Şekil 1. Ecoli veri seti deneyleri sonuç dağılımları için çeyrekler açıklığı grafikleri 
Tablo 2. Veri Setleri

\begin{tabular}{|c|c|c|c|c|c|c|c|}
\hline Data seti & Alanı & $\begin{array}{l}\text { Örnek } \\
\text { Sayısı }\end{array}$ & Sinıflar & $\begin{array}{c}\text { Sinıflardaki } \\
\text { Örnek } \\
\text { Sayısı } \\
\end{array}$ & Nitelikler & $\begin{array}{l}\text { Min. } \\
\text { Değer }\end{array}$ & $\begin{array}{l}\text { Maks. } \\
\text { Değer }\end{array}$ \\
\hline \multirow{8}{*}{ Ecoli } & \multirow{8}{*}{ Biyoinformatik } & \multirow{8}{*}{336} & $\mathrm{cp}$ & 143 & $\mathrm{mcg}$ & 0 & 0,89 \\
\hline & & & im & 77 & gvh & 0,16 & 1 \\
\hline & & & $\mathrm{pp}$ & 52 & lip & 0,48 & 1 \\
\hline & & & $\mathrm{imU}$ & 35 & chg & 0,5 & 1 \\
\hline & & & om & 20 & aac & 0 & 0,88 \\
\hline & & & omL & 5 & alm1 & 0,03 & 1 \\
\hline & & & $\mathrm{imL}$ & 2 & alm2 & 0 & 0,99 \\
\hline & & & $\mathrm{imS}$ & 2 & & & \\
\hline \multirow{9}{*}{ Glass } & \multirow{9}{*}{ Fizik } & \multirow{9}{*}{214} & & & $\mathrm{Ri}$ & 1,51115 & 1,53393 \\
\hline & & & & & $\mathrm{Na}$ & 10,73 & 17,38 \\
\hline & & & 1 & 70 & $\mathrm{Mg}$ & 0,0 & 4,49 \\
\hline & & & 2 & 76 & $\mathrm{Al}$ & 0,29 & 3,5 \\
\hline & & & 3 & 17 & $\mathrm{Si}$ & 69,81 & 75,41 \\
\hline & & & 5 & 13 & $\mathrm{~K}$ & 0,0 & 6,21 \\
\hline & & & 6 & 9 & $\mathrm{Ca}$ & 5,43 & 16,19 \\
\hline & & & 7 & 29 & $\mathrm{Ba}$ & 0,0 & 3,15 \\
\hline & & & & & $\mathrm{Fe}$ & 0,0 & 0,51 \\
\hline \multirow{4}{*}{ Iris } & \multirow{4}{*}{ Yaşam } & \multirow{4}{*}{150} & & & sepal_uzunluk & 4,3 & 7,9 \\
\hline & & & Setosa & 50 & sepal_genişlik & 2,0 & 4,4 \\
\hline & & & Versicolor & 50 & petal_uzunluk & 1,0 & 6,9 \\
\hline & & & Virginica & 50 & petal_genişlik & 0,1 & 2,5 \\
\hline
\end{tabular}

Tablo 3. Ecoli veri seti için karş̧laştırmalı "doğruluk" değeri sonuçları

\begin{tabular}{|c|c|c|c|c|c|c|c|}
\hline \multirow{2}{*}{$\begin{array}{c}\text { Data Set } \\
\text { Ecoli }\end{array}$} & \multirow{2}{*}{\multicolumn{2}{|c|}{ Karar Ăgacı }} & \multirow{2}{*}{\multicolumn{2}{|c|}{$\begin{array}{l}\text { JRIP } \\
0,806\end{array}$}} & \multirow{2}{*}{$\begin{array}{c}\text { Naive Bayes } \\
0,854 \\
\end{array}$} & \multirow{2}{*}{$\begin{array}{l}\text { DVM } \\
0,842 \\
\end{array}$} & \multirow{2}{*}{$\begin{array}{l}\text { AoA } \\
0,945 \\
\end{array}$} \\
\hline & & & & & & & \\
\hline Sinif & Doğruluk & \multicolumn{5}{|c|}{ Ecoli veri seti 1} & \\
\hline $\mathrm{cp}$ & 0,936 & \multicolumn{6}{|c|}{ EĞER $0,160<$ gvh $<0,581$ VE $0,030<$ alm $1<0,521$ İSE cp } \\
\hline im & 0,919 & \multicolumn{6}{|c|}{ EĞER $0,000<\operatorname{mcg}<0,633$ VE $0,596<$ alm $1<0,940$ İSE im } \\
\hline $\operatorname{imS}$ & 0,995 & \multirow{2}{*}{\multicolumn{6}{|c|}{$\begin{array}{c}\text { EĞER } 0,600<\operatorname{mcg}<0,879 \text { VE } 0,467<\text { gvh }<0,892 \text { VE } 0,744<\operatorname{lip}<0,974 \text { VE } 0,303<\text { aac }<0,541 \text { İSE imS } \\
\text { EĞER } 0,327<\operatorname{mcg}<0,880 \text { VE } 0,169<\text { gvh }<0,752 \text { VE } 0,861<\operatorname{lip}<1,000 \text { VE } 0,426<\text { aac }<0,527 \text { VE } 0,711<\operatorname{alm} 2<0,938 \\
\text { İSE } \operatorname{imL}\end{array}$}} \\
\hline $\mathrm{imL}$ & 1 & & & & & & \\
\hline $\mathrm{imU}$ & 0,946 & \multicolumn{6}{|c|}{ Ĕ̈ER $0,743<\operatorname{mcg}<0,889$ VE $0,001<$ aac $<0,876$ VE $0,442<$ alm $2<0,939$ İSE imU } \\
\hline om & 0,995 & \multicolumn{6}{|c|}{ EĞER $0,544<\operatorname{mcg}<0,802$ VE $0,637<$ aac $<0,880$ VE $0,142<$ alm2 $<0,604$ İSE om } \\
\hline omL & 1 & \multicolumn{6}{|c|}{ EĞER $0,879<\operatorname{lip}<1,000$ VE $0,165<$ alm $2<0,502$ İSE omL } \\
\hline $\mathrm{pp}$ & 0,982 & \multicolumn{6}{|c|}{ EĞER $0,567<\operatorname{mcg}<0,831$ VE $0,561<$ gvh $<0,866$ VE $0,077<$ aac $<0,634$ İSE pp } \\
\hline
\end{tabular}

Tablo5. Ecoli veri seti için istatistiksel sonuçlar

\begin{tabular}{ccccccccc}
\hline & cp & im & imS & imL & imU & om & omL & pp \\
\hline Min & 0,701 & 0,769 & 0,995 & 0,995 & 0,895 & 0,941 & 0,986 & 0,846 \\
Maks & 0,936 & 0,919 & 0,995 & 1,000 & 0,946 & 0,995 & 1,000 & 0,982 \\
Ortalama & 0,901 & 0,850 & 0,995 & 0,995 & 0,901 & 0,958 & 0,990 & 0,935 \\
Ortanca & 0,920 & 0,860 & 0,995 & 0,995 & 0,896 & 0,950 & 0,986 & 0,932 \\
Std.Sapma & 0,052 & 0,042 & $2,66454 \mathrm{E}-14$ & 0,0003 & 0,009 & 0,017 & 0,005 & 0,031 \\
\hline
\end{tabular}

Kriminal soruşturma çalışmalarından elde edilen bir veri seti olan Glass, çalışılan diğer bir arama uzayıdır. Toplamda altı sınıflı bu veri seti için yapılan deneylerden birinde elde edilen doğruluk değerleri ve bu değerleri sağlayan kurallar Tablo 6 ve 7'de paylaşılmıştır. Tablo 8 ise bu veri seti ile yapılan, toplamda 120 farklı deneye ait istatiksel sonuçları göstermektedir. Tablo 7'deki deneye ait sonuçlar dikkate alındığında, sınıf ağırlık değerlerine göre ortalama doğruluk değerinin 0,676 olduğu görülmektedir. $\mathrm{Bu}$ değer, diğer standart sınıflandırma algoritma sonuçlarına göre en iyi dördüncü değer olmuştur. $\mathrm{Bu}$ veri seti için en iyi sonucu $\mathrm{k}-\mathrm{NN}$ algoritması elde etmiştir. En kötü sonuç ise Naive Bayes'e aittir. Genel başarım olarak uyarlanmış AOA yöntemi her ne kadar vasat bir görüntü verse de kendisinden daha iyi sonuç veren algoritmalara yakın değerler üretebilmiştir. Sınıf bazında incelendiğinde bu veri setinde başarımı düşüren sınıf aslında "üç" sınıfıdır. $\mathrm{Bu}$ sınıfa ait başarılı bir kural çıkarımı tam olarak elde edilememiştir. Bununla beraber son üç sınıfta başarım değerleri yüksektir. Öte yandan bu sınıflarda yoğunluk katsayılarının düşük olması nedeniyle başarıma çok fazla etki etmemiştir. İstatistiksel sonuçları oluşturan deney sonuç dağılımları Şekil 2'de verilmiştir. Sadece bir sınıfı için ayrık değerlerin oluştuğu deneylerde üç ve üstü sınıflarda açıklık düşük ve kararlılık yüksektir.

Her biri elli örnek içeren üç sınıflı Iris, literatürde iyi bilinen bir veri seti olup son deneyler bu veri seti ile gerçekleştirilmiştir. $\mathrm{Bu}$ veri seti ile toplamda 60 farklı deney yapılmıştır. Tablo 9 ve 10 bu deneylerden birine ait sonuçları ve diğer algoritmalara ait sonuçları karşılaştırmalı göstermektedir. Tüm deneyler için elde edilen istatistiksel sonuçlar ise Tablo 11 'de paylaşılmıştır. 


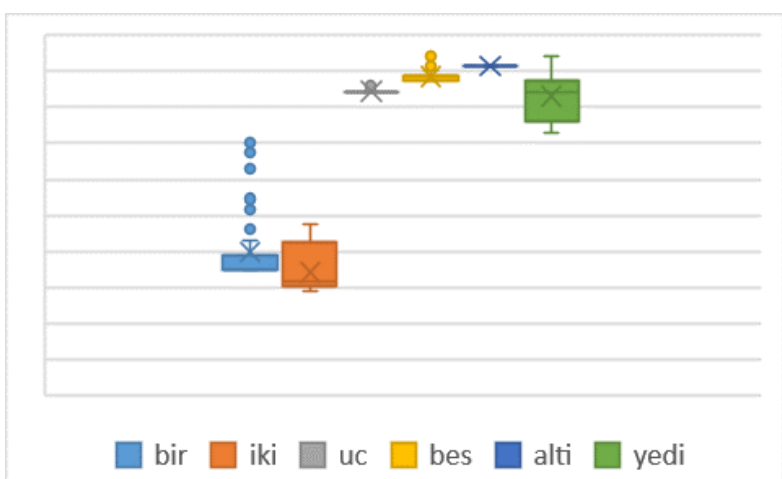

Şekil 2. Glass veri seti deneyleri sonuç dağılımları için çeyrekler açıklığı grafikleri

Kural çıkarım temelli AOA en iyi sonuçlardan birini bu veri setinde elde etmiştir. Standart sinıflandırma algoritmalarında en iyi sonuç 0,966 ile JRIP tarafından elde edilmişken, uyarlanmış AOA bu veri setinde tüm sınıflar için 0,977 ağırlıklı ortalama değerine ulaşmayı başarmıştır. Sınıf bazında değerlendirildiğinde tüm sınıfların yoğunluk katsayıları aynı olduğu için ağırlıklı ortalamada etkileri aynı olmuştur. Setosa sınıfında başarım \%100 oranına ulaşmayı başarabilmiştir. Diğer iki sınıfta da ortalama başarım 0,965 olmuştur. Karar ağac1 algoritması, Ecoli veri setinde olduğu gibi en düşük başarım değerine sahip algoritma olmuştur. Şekil 3 'te verilen sonuç grafikleri incelendiğinde her ne kadar Setosa ve Versicolor'da ayrık değerler olsa da başarımın genellikle yüksek olduğu görülmektedir.

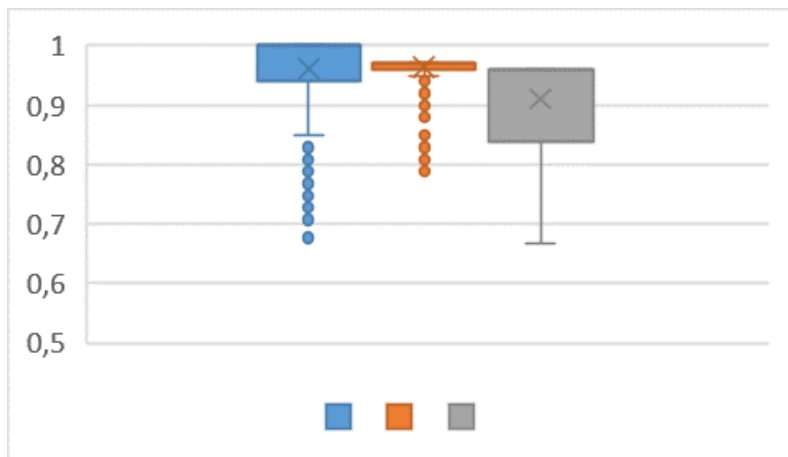

Şekil 3. Iris veri seti deneyleri sonuç dağılımları için çeyrekler açıklığı grafikleri

Tablo 6. Glass veri seti için karșılaştırmalı "doğruluk" değeri sonuçları

\begin{tabular}{ccccccc}
\hline $\begin{array}{c}\text { Data } \\
\text { Seti }\end{array}$ & Karar Ă̆acı & k-NN & JRIP & Naive Bayes & DVM & AoA \\
\hline Glass & 0,700 & 0,705 & 0,696 & 0,495 & 0,574 & 0,676 \\
\hline
\end{tabular}

Tablo7. Glass veri seti kuralları

\begin{tabular}{|c|c|c|}
\hline Sinif & Doğruluk değeri & Kural \\
\hline bir & 0,651 & EĞER $1,517<\mathrm{RI}<1,530 \mathrm{VE} 2,628<\mathrm{Mg}<3,758 \mathrm{VE} 7,550<\mathrm{Ca}<12,281$ İSE bir \\
\hline iki & 0,580 & EĞER $11,484<\mathrm{Na}<15,111 \mathrm{VE} 1,408<\mathrm{Al}<2,680 \mathrm{VE} 6,717<\mathrm{Ca}<8,360$ İSE iki \\
\hline üç & 0,322 & EĞER $70,315<\mathrm{Si}<73,056 \mathrm{VE} 3,654<\mathrm{K}<4,765 \mathrm{VE} 6,607<\mathrm{Ca}<6,923$ İSE uc \\
\hline beş & 0,972 & EĞER $1,021<\mathrm{Al}<2,546 \mathrm{VE} 71,616<\mathrm{Si}<74,376 \mathrm{VE} 11,317<\mathrm{Ca}<12,920$ İSE bes \\
\hline alt1 & 0,957 & EĞER $12,693<\mathrm{Na}<15,404 \mathrm{VE} 2,374<\mathrm{Mg}<2,580 \mathrm{VE} 71,459<\mathrm{Si}<72,593$ İSE alti \\
\hline yedi & 0,972 & EĞER $0,274<\mathrm{Ba}<2,058$ İSE yedi \\
\hline
\end{tabular}

Tablo8. Glass veri seti için istatistiksel sonuçlar

\begin{tabular}{ccccccc}
\hline & bir & iki & üç & beş & altı & yedi \\
\hline Min & 0,574 & 0,505 & 0,122 & 0,936 & 0,957 & 0,865 \\
Maks & 0,651 & 0,580 & 0,322 & 0,972 & 0,957 & 0,972 \\
Ortalama & 0,605 & 0,554 & 0,221 & 0,942 & 0,957 & 0,916 \\
Ortanca & 0,604 & 0,559 & 0,198 & 0,943 & 0,957 & 0,922 \\
Std.Sapma & 0,045 & 0,030 & 0,004 & 0,007 & $5,88418 \mathrm{E}-15$ & 0,032 \\
\hline
\end{tabular}

Tablo 9. Iris veri seti için karşılaştırmalı "doğruluk" değeri sonuçları

\begin{tabular}{ccccccc}
\hline Data Seti & Karar Ă̆acı & k-NN & JRIP & Naive Bayes & DVM & AoA \\
\hline Iris & 0,926 & 0,953 & 0,966 & 0,96 & 0,960 & 0,977 \\
\hline
\end{tabular}

Tablo 10. Iris veri seti kuralları

\begin{tabular}{ccc}
\hline Sinıf & Doğruluk değeri & Kural \\
\hline Setosa & 1 & EĞER $1,000<$ petal_length $<2,126$ İSE setosa \\
Versicolor & 0,970 & EĞER $2,856<$ petal_length $<5,109$ VE $0,811<$ petal_width $<1,786$ İSE versicolor \\
Virginica & 0,960 & EĞER $1,649<$ petal_width $<2,500$ İSE virginica \\
\hline
\end{tabular}

Tablo 11. Iris veri seti için istatistiksel sonuçlar

\begin{tabular}{cccc}
\hline & setosa & versicolor & virginica \\
\hline Min & 0,677 & 0,788 & 0,667 \\
Maks & 1 & 0,970 & 0,960 \\
Ortalama & 0,961 & 0,963 & 0,914 \\
Ortanca & 1 & 0,970 & 0,960 \\
Std.Sapma & 0,060 & 0,014 & 0,070 \\
\hline
\end{tabular}




\section{SONUÇLAR}

Ayrıklaştırma safhasından dolayı standart kural çıkarım tekniklerinde başarımlar olumsuz etkilenebilmektedir. Optimizasyon temelli yaklaşımların sürekli verileri üzerinde ayrıklaştırma yapmadan çalışabilmesi onlara bu konuda önemli avantajlar sağlayabilir. $\mathrm{Bu}$ amaçla bu çalışmada, optimizasyon temelli kural çıkarımına odaklanılmıştır. Çalışma, son yılların başarılı bitki zekası temelli meta sezgisel yaklaşımlarından olan Ayçiçeği Optimizasyon Algoritmasını (AOA) kullanmıştır. Bu amaçla bu problem için uygun temsil biçimi ve uygunluk fonksiyonu belirlenmiştir. Önerilen yaklaşım üç farklı disiplinde toplanmış olan veri seti için test edilmiş ve sonuçları literatürde iyi bilinen standart sınıflandırma algoritmaları ile karşılaştırılmıştır. Toplamda 340 ayrı deney gerçekleştirilmiştir. Başarım metriği olarak doğruluk kullanılmıștır. Her bir sınıf için gerçekleştirilen deneyler sonucunda, ilgili veri seti için sonuç doğruluk değeri sınıf yoğunluk katsayılarına göre hesaplanmıştır. Yapılan deneylerde, iki veri setinde en iyi sonuç, önerilen AOA temelli yaklaşımla elde edilmiştir. Elde edilen kurallar ve yapılan tüm deneylere ait istatistiksel sonuçlar önerilen uyarlanmış AOA yaklaşımının başarısını ispatlamıştır. Öte yandan kullanılan standart sınıflandırma algoritmaları içinde Naive Bayes ve DVM daha başarılı olurken Karar Ağacı iki veri setinde en düşük sonuçlara sahip olmuştur. Yazarlar bundan sonraki çalışmalarında çok amaçlı ve hibrid kural çıkarım çalışmalarına odaklanacaktır.

\section{KAYNAKLAR}

[1] Savargiv M, Masoumi B, Keyvanpour MR. A new ensemble learning method based on learning automata. Journal of Ambient Intelligence and Humanized Computing.2020; 1-16.

[2] Liu J, Chi Y, Liu Z, He S. Ensemble multiobjective evolutionary algorithm for gene regulatory network reconstruction based on fuzzy cognitive maps. CAAI Transactions on Intelligence Technology. 2019; 4(1): 24-12.

[3] He C, Ma M, Wang P. Extract InterpretabilityAccuracy balanced Rules from Artificial Neural Networks: A Review. Neurocomputing. 2020; 387(C):346-12.

[4] Kiziloluk S, Alatas B. Automatic mining of numerical classification rules with parliamentary optimization algorithm. Advances in Electrical and Computer Engineering. 2015; 15(4): 17-8.

[5] Phoungphol P, Zhang Y, Zhao Y. Robust multiclass classification for learning from imbalanced biomedical data. Tsinghua Science and Technology. 2012; 17(6): 619-9.

[6] Gündoğan KK, Alataş B, Karci A. Mining Classification Rules by Using Genetic Algorithms with Nonrandom Initial Population and Uniform Operator. Turk J Elec Engin. 2004;12(1): 43-9.

[7] Pourpanaha F, Limb CP, Saleha JM. A hybrid model of fuzzy ARTMAP and genetic algorithm for data classification and rule extraction. Expert Systems with Applications. 2016;49:74-11.
[8] Tripathy S, Hota S, Satapathy P. MTACO-Miner: Modified Threshold Ant Colony Optimization Miner for Classification Rule Mining. Emerging Research in Computing, Information, Communication and Applications. Elsevier; 2013.p.1-5.

[9] Taboada K, Mabu S, Gonzales E, Shimada K, Hirasawa K. Fuzzy Classification Rule Mining Based on Genetic Network Programming Algorithm. IEEE Conference on Systems, Man, and Cybernetics. USA: 2009. p. 3960-6.

[10] Dehuri S, Cho S. Multi-objective Classification Rule Mining Using Gene Expression Programming. Third International Conference on Convergence and Hybrid Information Technology. Korea:2008. p. 755-7.

[11] Zhong-Yang X, Lei Z, Yu-Fang Z. A Classification Rule Mining Method Using Hybrid Genetic Algorithms. IEEE Region 10 Conference Tencon. Thailand: 2004. p.207-4.

[12] Ghobaei-Arani M, Souri A, Safara F, Norouzi M. An efficient task scheduling approach using mothflame optimization algorithm for cyber-physical system applications in fog computing. Transactions on Emerging Telecommunications Technologies. 2019; 31(1):1-14.

[13] Safara F, Mohammed AS, Potrus MY, Ali S, Tho QT, Souri A, et al. An Author Gender Detection Method Using Whale Optimization Algorithm and Artificial Neural Network. IEEE Access.2020; 8:48428-10.

[14] Yildirim G, Alatas B. (2021), New Adaptive Intelligent Grey Wolf Optimizer based MultiObjective Quantitative Classification Rules Mining Approaches. Journal of Ambient Intelligence and Humanized Computing. 2021; https://doi.org/10.1007/s12652-020-02701-9.

[15] Akyol S, Alataş B. Plant intelligence based metaheuristic optimization algorithms. Artificial Intelligence Review. 2017;47:417-45.

[16] Qais MH, Hasanien HM, Alghuwainem S. Identification of electrical parameters for threediode photovoltaic model using analytical and sunflower optimization algorithm. Applied Energy. 2019;250:109-8

[17] Gomes GF, Almeida FA. Tuning metaheuristic algorithms using mixture design:Application of sunflower optimization for structural damage identification. Advances in Engineering Software. 2020;149:102877

[18] Yuan Z, Wang W, Wang H, Razmjooy N. A new technique for optimal estimation of the circuitbased PEMFCs using developed Sunflower Optimization Algorithm. Energy Reports. 2020; 6: 662-9.

[19] Hussien AM, Hasanien HM, Mekhamer SF. Sunflower optimization algorithm-based optimal PI control for enhancing the performance of an autonomous operation of a microgrid. Ain Shams Engineering Journal. 2021; 12(2):1883-10.

[20] Shaheen MAM, Hasanien HM, Mekhamer SF, Talaat HEA. Optimal Power of Power Systems Including Distributed Generation Units Using 
Sunflower Optimization Algorithm. IEEE Access. 2019; 7: 109289-11.

[21] Alshammari BM, Guesmi T. New Chaotic Sunflower Optimization Algorithm for Optimal Tuning of Power System Stabilizers. Journal of Electrical Engineering \& Technology. 2020; 15: 1985-12.

[22] Gomes GF, Cunha Jr SS, Ancelotti Jr AC. A sunflower optimization (SFO) algorithm applied to damage identification on laminated composite plates. Engineering with Computers. 2019; 35: 6197.

[23] Proença HM, Leeuwen M. Interpretable multiclass classification by MDL-based rule lists. Information Sciences. 2020; 512: 1372-21.

[24] Miranda TZ, Sardinha DB, Cerri R. (2019). Preventing the Generation of Inconsistent Sets of Classification Rules. Expert Systems with Applications. 2019;165. 